\title{
Identifikasi Makna Ukiran Alang (Lumbung Padi)
}

\section{Yohanis Padallingan ${ }^{1}$, Gidion Aryo Nugaha Pongdatu ${ }^{2}$}

${ }^{1}$ (Pendidikan Guru Sekolah Dasar, Fakultas Keguuan dan Ilmu Pendidikan/Univesitas Kristen Indonesia Toraja, Indonesia)

${ }^{2}$ (Teknik Informatika, Fakultas Teknik/Univesitas Kristen Indonesia Toraja, Indonesia)

* Corresponding Author. E-mail: ${ }_{\text {yohanispadallingan@ukitoraja.ac.id }}$

Receive: 13/05/2021

Accepted: $23 / 08 / 2021$

Published: 01/10/2021

\begin{abstract}
Abstrak
Tujuan diadakannya penelitian ini adalah 1) Mengetahui latar belakang dari ukiran pa' barre allo, $p a^{\prime}$ manuk londong, $p a^{\prime}$ tedong, dan $p a^{\prime}$ don bolu. 2) Mengetahui pesan moral dari ukiran pa' barre allo, $p a^{\prime}$ manuk londong, $p a^{\prime}$ tedong, dan $p a^{\prime}$ don bolu. Penelitian ini diadakan di Lembang Sa'dan Ulusalu, tepatnya di Kecamatan sa'dan, Toraja Utara yang berlangsung selama 1 tahun. Penelitian ini diharapkan mampu bermanfaat bagi: 1) bagi masyarakat yaitu menjadi bahan masukan dan referensi dalam mengembangkan wawasan dan memberi informasi tentang pesan moral dalam ukiran Toraja. 2) bagi wisatawan yaitu sebagai bahan dalam menambah wawasan tentang kebudayaan Toraja khususnya bagi wisatawan lokal maupun mancanegara yang baru pertama kali mengenal secara langsung budaya Toraja. 3) bagi Pemerintah Daerah yaitu membantu Pemerintah Daerah dalam mengembangkan dan memanfaatkan secara maksimal potensi pariwisata yang ada dalm ukiran Toraja 4) bagi Dinas Pariwisata yaitu sebagai bahan acuan dan referensi dalam pengelolaan pariwisata, 5) Bagi siswa Sekolah Dasar sebagai bahan referensi untuk mengadopsi nilai-nilai moral dan nilai-nilai sosial. Hasil penelitian menunjukkan bahwa ukiran Toraja atau passura' Toraya sudah lama dikenal oleh masyarakat Toraja sebagai bentuk sarana berkomunikasi yang dikiaskan melalui simbol. Dari setiap simbol tersebut terkandung pesan-pesan moral yang disampaikan oleh leluhur kepada anak cucunya agar kelak keturunan dan anak cucunya senantiasa hidup dalam nilai-nilai luhur budaya Toraja.nilai-nilai moral yang terkandung dalam ukiran Toraja berdasarkan hasil penelitian seperti kejujuran, kebijaksanaan, gotong royong dan menjadi cahaya bagi sesama, dan terpenting bagi siswa sekolah dasar.
\end{abstract}

Kata Kunci: Ukiran, Alang, Sekolah Dasar

\begin{abstract}
The purpose of this research is 1) to know the background of the carvings of pa 'barre allo, pa' manuk

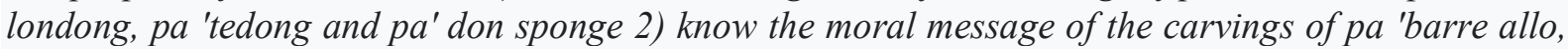
$p a^{\prime}$ manuk londong, $p a$ 'tedong and $p a^{\prime}$ don sponge. This research was carried out in Lembang Sa'dan Ulusalu, Sa'dan District, North Toraja, for a one year. This research is expected to be useful to: 1) the community as input and reference material in developing knowledge and providing information about moral messages in Toraja carvings. 2) for tourists, namely as an ingredient to gain insight into the Toraja culture, especially for local and foreign tourists who are quantitatively slowing down the Toraja culture for the first time. 3) for the regional government, to supporting the regional government in the development and maximum use of the tourist potential that is present in Toraja carvings 4) for the tourism office, as a reference to tourism management 5), fo the pimary school
\end{abstract}


students as a reference to moral values and social values. The results of the study show that Toraja carvings or Passura 'Toraya' have long been known by the Toraja as a form of communication represented by symbols. Each of these symbols contains moral messages that the ancestors conveyed to their children and grandchildren so that their descendants and later always live in the noble values of the Torasonga Royong culture and become a light for others and especially for pimary school students.

\section{Keywords: Cavings, Alang (Rice Barn), Primary School Students}

\section{Pendahuluan}

Kebudayaan memiliki sifat yang dinamis berkembang, berubah, dan musnah sesuai dengan perkembangan zaman. Hal ini dapat terlihat pada kebudayaan Toraja, yang secara administratif penduduk asli yang bermukim di Kabupaten Tana Toraja dan Toraja Utara Provinsi Sulawesi Selatan, dengan kondisi topografi berbukit dengan luas wilayah $3000 \mathrm{Km}$ persegi yang berbatasan dengan Kabupaten Luwu, Enrekang, Mamuju, Pinrang, dan Polewali Mandar.

(Salam Husain, 2015) Menyatakan bahwa orang Bugis-lah yang yang menamakan etnik Toraja dengan sebutan Toraja dari kata to rajang atau to riaja yang bermakna orang dari sebelah barat atau utara. Istilah Toraja juga biasa dikaitkan dengan artefak budaya yang dihasilkan oleh masyarakat Toraja seperti seni rupa (patung, tenun, ukir) dan seni bangunan Toraja (tongkonan dan lumbung padi). Kebudayaan Toraja merupakan warisan yang turun temurun diwariskan oleh para leluhur Toraja dari generasi ke generasi.

Di zaman modern ini sikap pragmatis pada sebagian generasi muda Indonesia saat ini mengakibatkan nilai-nilai luhur budaya bangsa kian terkikis, masuknya budayabudaya baru dalam tatanan hidup masyarakat membuat budaya dan kearifan lokal kian semakin terpinggirkan bahkan hampir tidak mendapat perhatian dari sebagian generasi muda saat ini.

Ketika generasi muda Toraja berbondong-bondong mengeksplorasi budaya dari daerah lain, sementara para pelancong dari luar negeri justru berlombalomba datang ke Toraja untuk mengeksplorasi budaya dan kearifan lokal yang ada dalam tatanan hidup masyarakat
Toraja yang dikenal sangat kental akan adat dan tradisinya yang masih terjaga hingga sekarang.

(Salam Husain, 2015) Menyatakan peninggalan budaya Toraja dalam bentuk rupa (visual) tersebar hampir di seluruh wilayah Toraja. Masyarakat etnis Toraja masih teguh mempertahankan warisan dari leluhur mereka, salah satu yang paling mencolok dan dapat kita temui adalah ukiran Toraja (Passura' Toraya). Ukiran Toraja merupakan karya seni ukir kayu tradisional di Toraja yang secara harfiah berarti tulisan.

Setiap kehidupan masyarakat toraja sehari-hari selalu berkaitan dengan adat budaya, budaya Toraja terkenal akan keunikan dan masyarakatanya yang terkenal santun dan menjunjung asas kebersamaan dan gotong royong. Di dalam setiap ukiran Toraja terdapat pesan tersembunyi yang masih belum tersingkapkan secara luas hingga saat ini, ukiran Toraja mengandung pesan yang menyangkut moral atau etika dalam menjalani kehidupan di alam ini.

Ukiran Toraja memiliki ciri khas tersendiri dengan desain dekoratif, dan berwarna warni yang memiliki makna simbolik dari setiap ukirannya berdasarkan kepercayaan aluk todolo, ukiran toraja dibuat pada bahan kayu dan menjadi hiasan dengan makna tertentu pada rumah adat tongkonan.

Ukiran Toraja memiliki berbagai macam motif dan bentuk yang berbeda yang dipasang di rumah adat Toraja, setiap ukiran Toraja memiliki makna yang sombolis dan mengandung pesan-pesan tertentu, terdapat empat ukiran yang sangat sering diguanakan untuk menghiasi rumah adat (tongkonan) yakni ukiran pa' barre allo 
yang menyimbolkan ketuhanan dan kesatuan, pa' manuk londong yang menyimbolkan tata hukum, pa' tedong yang menyimbolkan lambang kemakmuran, dan pa' don bolu yang menyimbolkan rasa hormat dan kasih persaudaraan.

Moral mengatur perilaku setiap masyarakat saat bersosialisasi dengan masyarakat lainnya dalam satu kesatuan wilayah, moral menyangkut tingkah laku, akhlak, dan budi pekerti yang menggambarkan karakter diri sesorang. Moral adalah hasil produk dari suatu budaya manusia yang memiliki fungsi yang sangat penting dalam mewujudkan masyarakat yang memiliki nilai kemanusiaan dan keharmonisan.

Moral adalah suatu hal yang berkaitan dengan ajaran yang diterima dalam hal sikap, etika, perbuatan, budi pekerti. Sebagai manusia kita tidak dapat menutup mata akan kondisi moral yang ada di Indonesia saat ini, kondisi moral semakin hari semakin memprihatinkan dengan banyaknya kasus-kasus kekerasan diluar sana yang memperlihatkan perilaku immoral.

Ukiran Toraja mengisahkan kebijaksanaan manusia Toraja yang diwariskan kepada anak cucunya agar hidup sesuai dengan harapan para leluhur toraja yang dimuat dalam bentuk simbol ukiran toraja.Hidup sesuai harapan para leluhur artinya hidup selaras dengan kebiasaan leluhur Toraja yang mengajarkan hidup dalam kesucian, kejujuran, dan hidup dalam kebersamaan. Setiap pesan-pesan dari para leluhur toraja telah dimuat sedemikian rupa dalam bentuk simbol yang bermakna agar dapat dipahami oleh para generasi penerus yang akan datang.

Dari uraian di atas maka dapat dilihat bahwa di dalam ukiran Toraja terkandung makna yang tersembunyi yang berisi nilainilai moral yang perlu dilestarikan dan perlu diketahui secara mendalam oleh para generasi penerus yang akan datang, dengan menggali lebih dalam makna dari ukiran Toraja kita dapat menjadikan pesan moral dari sebuah ukiran Toraja menjadi pedoman dalam bertingkah laku generasi muda yang akan datang.

Berdasarkan uraian latar belakang di atas, maka perlu diangkat sebuah judul tentang "Analisis Pesan Moral Dalam Ukiran Toraja"

\section{Metode}

Penelitian ini menggunakan metode penelitian kualitatif dengan jenis penelitian deskriptif. (Siyoto Sodik, 2015 : 11) Menyatakan "Penelitian kualitatif menekankan bahwa kenyataan itu berdimensi jamak, interaktif dan suatu pertukaran pengalaman sosial yang diinterpretasikan oleh individu-individu. Penelitian kualitatif ditujukan untuk memahami fenomena-fenomena sosial dari sudut atau perspektifpartisipan".

Penelitian deskriptif adalah penelitian yang diarahkan untuk memberikan gejalagejala, fakta-fakta atau kejadian secara sistematis dan akurat, mengenai sifat-sifat populasi atau daerah tertentu (Zuriah, 2006 : 47). Dalam penelitian ini terdapat dua sumber data yang digunakan yaitu data primer yaitu data yang diperoleh secara langsung dari Tokoh Adat Sillanan dan data sekunder yaitu data yang diperoleh secara sekunder dari buku maupun jurnal.

Teknik pengumpulan data yang digunakan dalam penelitian ini adalah (1) Wawancara, wawancara dalam penelitian terjadi saat peneliti berbincang langsung dengan narasumber yang akan memberikan jawaban. Dalam penelitian ini subjek wawancara adalah Tokoh Adat Lembang Sa'dan ulusalu dan Masyarakat sekitar Perkampungan Adat Sa'dan dengan menggunakan wawancara semiterstruktur dimana pelaksanaannya lebih bebas dimana pihak yang diwawancarai diminta pendapat dan idenya; (2) Observasi, observasi dalam penelitian ini dilakukan dengan cara melakukan pengamatan langsung di rumah adat tongkonan yang terdapat ukiran $p a$ ' bare allo, pa' manuk londong, pa' tedong dan pa' don bolu; (3) Dokumentasi, dokumentasi dalam penelitian ini 
digunakan untuk memperoleh data pelengkap seperti gambar ukiran Toraja.

Analisis data dalam penelitian ini meliputi : (1) Reduksi Data, Mereduksi data berarti merangkum, memilih hal-hal yang pokok, memfokuskan pada hal-hal yang penting, dicari temadan polanya dan membuang yang tidak perlu. Pada penelitian ini peneliti akan memilih hal-hal pokok yang berkaitan dengan pesan moral dalam ukiran Toraja dan fokus pada hal yang penting. (2) Penyajian data, Penyajian data adalah sekumpulan informasi tersusun yang memberi kemungkinan adanya penarikan kesimpulan.Penyajian data dalam penelitian ini diuraikan secara singkat dengan alasan untuk menyederhanakan tanpa mengurangi isi dari pesan moral dalam ukiran Toraja. Peneliti akan berupaya mengklasifikasikan dan menyajikan data berdasarkan pokok permasalahan. Penyajian data oleh peneliti yaitu data yang diperoleh dari pengumpulan data pesan moral dalam ukiran Toraja di Perkampungan Adat Tua Sillanan Lembang Sillanan Kecamatan Gandangbatu Sillanan. (3) Kesimpulan atau verifikasi, Kesimpulan atau verifikasi adalah tahap akhir dalam proses analisa data. Pada bagian ini peneliti mengutarakan kesimpulan dari data-data yang telah diperoleh. Setelah penyajian data peneliti akan kembali mereduksi data tentang pesan moral dalam ukiran Toraja untuk ditarik kesimpulan.

Triangulasi sumber dalam penelitian ini untuk menguji kredibilitas data yang dilakukan dengan cara mengecek data yang telah diperoleh melalui beberapa sumber, data yang diperoleh dari Tokoh adat dan masyarakat sekitar dideskripsikan dan dikategorikan kemudian akan dianalisis oleh peneliti sehingga menghasilkan kesimpulan.

\section{Hasil dan Pembahasan}

Proses penelitian dan pengumpulan data dilaksanakan di Perkampungan adat Sa'dan tepatnya di Lembang Sa'dan Ulusalu Kecamatan Sa'dan , yang melibatakan Tokoh Adat sebanyak 4 orang dan beberapa aparat Lembang.

Keempat informan tersebut adalah Bapak Marthen Galigo umur 75 tahun alamat Rante Ba'tan dan berprofesi sebagai Tokoh adat di Lembang Sillanan informan tersebut dipilih karena memiliki pengetahuan yang luas mengenai adat dan budaya Toraja khusunya di Lembang Sillanan, informan 2 Abe' Asse' umur 49 tahun, beliau merupakan kepala dusun Kaloan Lembang Sillanan informan tersebut dipilih berdasarkan rekomendasi dari Bapak Marthen Galigo, informan 3 John Sitha umur 69 tahun beliau merupakan salah satu tokoh kebudayaan di Lembang Sillanan, dan informan 4 adalah Paulus Tumba Padidi umur 49 tahun yang berprofesi sebagai honorer purbakala.

Ukiran toraja pada dasarnya digunakan oleh masyarakat Toraja sebagai salah satu bentuk sarana berkomunikasi untuk menyampaikan pesan moral kepada masyarakat maupun kepada seluruh anggota keturunan. Rumah adat Toraja (tongkonan) dan lumbung dipenuhi ukiran Toraja yang sarat akan nilai-nilai moral.

Dari hasil observasi peneliti memperoleh data yaitu semua tongkonan yang ada di Lembang Sillanan semuanya memiliki ketiga ukiran yang terpasang di setiap tongkonan yakni pa' bare allo, pa' manuk londong, dan pa' tedong, sementara itu ukiran pa' don bolu hanya terdapat di beberapa tongkonan saja hal ini dikarenakan menurut informan ukiran tersebut adalah ukiran yang sudah lama atau biasa disebut passura' tojolo.

Dalam penelitian ini terdapat empat ukiran Toraja yang yang akan dianalisis oleh peneliti yaitu ukiran pa' bare allo, pa' manuk londong, pa' tedong dan pa' don bolu. Dari keempat tersebut berdasarkan hasil tinjauan pustaka memiliki makna masingl-masing yakni :

\section{Ukiran Pa' bare Allo}

Dalam ukiran pa' bare allo motif yang paling mencolok dan paling kelihatan adalah cahaya matahari yang muncul dari 
satu titik dari bulatan sinar matahari, dalam konteks istilah kabarrean allo biasanya merujuk pada suatu istilah daerah yang memeiliki gelar kebangsawanan yang diambil dari matahari. Ukiran ini memiliki makna yaitu supaya manusia yang datang dan turun dari tongkonan hendaknya senantiasa bersinar dan bercahaya dimana pun dia berada.

\section{Ukiran Pa' Manuk Londong}

Dalam ukiran Toraja terdapat dua jenis ayam yang disandingkan di depan rumah atau lumbung (ayam sella mabusa dan sella merah) kedua ayam tersebut bertengger di atas ukiran pa' bare allo. Ukiran pa' manuk londong yang ditempatkan pada tongkonan pada dasarnya menggambarkan status dari orang yang berada di atas rumah tersebut. Ukiran ini juga bermakna suatu kepastian.

\section{Ukiran Pa' Tedong}

Jenis ukiran yang dibahas disini adalah ukiran pa' tedong umum, Ukiran ini juga menggambarkan strata sosial yang bersangkutan atau pemilik rumah yang bersangkutan, tempat pemasangannya biasanya di sangkinan rumah atau lumbung. Ukiran ini memiliki makna kesejahteraan dan pencapaian dari pemilik tongkonan.

\section{Ukiran Pa' Don Bolu}

Sirih atau don bolu merupakan salah satu simbol yang memiliki makna yang amat besar dalam budaya Toraja, sirih dalam budaya Toraja sangat erat kaitannya dengan rasa persaudaraan dan simbol kebersihan hati. Makna dibalik ukiran ini pada menggambarkan status pemilik dan menunjuk pada rasa sikap hormat yang tulus dari pemilik tongkonan atau rumpun keluarga.

Setiap ukiran Toraja sudah pasti memiliki makna dan nilai filosofi yang terkandung dalam setiap ukiran tersebut, seperti yang telah disampaikan oleh beberapa narasumber yang telah peneliti wawancarai sebelumnya meskipun ada yang memiliki pandangan berbeda pada setiap ukiran, namun makna dari ukiran tersebut pada intinya tetap merujuk pada pesan-pesan moral yang disampaikan oleh leluhur Toraja kepada anak cucunya agar kelak anak cucunya senantiasa hidup sesuai pesan dari leluhur Toraja.

Sesuai dengan hasil penelitian, mulai dari observasi dan wawancara langsung di lapangan maka penulis menyimpulkan bahwa dalam ukiran Toraja terdapat pesan moral dalam keempat ukiran tersebut yakni ukiran pa' bare allo, ukiran pa' manuk londong, ukiran pa' tedong dan ukiran pa' don bolu.

\section{Pesan Moral Pa' Bare Allo Pa' Manuk Londong, Pa' Tedong dan Pa' Don Bolu}

Pesan moral dari ukiran ini adalah manusia harus menjadi cahaya dan memberi harapan hidup bagi orang yang sedang berada dalam kegelapan hidup. Menjadi cahaya dan harapan hidup bagi orang dalam kegelapan hidup artinya kita harus menjadi pribadi yang mampu menjadi penolong dan penasihat bagi orang yang sedang mengalami berbagai pergumulan hidup atau sedang berada dalam masalah. Menjadi cahaya bagi orang lain dapat juga kita wujudkan dengan cara memperlihatkan pribadi yang senatiasa menjadi pendengar dan penasihat yang baik bagi orang lain.

Pesan moral dalam ukiran pa' manuk londong adalah kita harus belajar dari sisi positif dari ayam jantan yang senantiasa bekerja keras, berani, dan disiplin dalam hal waktu. Ukiran ini juga mengajarkan kepada kita untuk senantiasa hidup dalam sebuah kepastian.

Pesan moral dari ukiran pa' tedong adalah kita harus berusaha mencapai citacita agar kelak kita bisa mempersembahkan yang terbaik bagi orang yang kita cintai. Mempersembahkan yang terbaik artinya orang Toraja harus memberikan kado atau sesuatu yang terbaik terbaik kepada orang yang dicintainya.

Pesan moral dalam ukiran pa' don bolu adalah kita harus senantiasa rendah hati dan hormat kepada sesama dalam kasih persaudaraan dan senantiasa hormat pada 
sang pencipta dalam setiap langkah kehidupan kita. Hormat kepada sesama artinya saling menghargai dan menghormati dalam kehidupan bersosialisasi dalam kehidupan bermasyarakat, terlebih lagi hormat kepada sang pencipta yang telah memberi nafas kehidupan bagi kita.

\section{Simpulan}

Berdasarkan hasil penelitian dan pembahasan maka kesimpulan yang dapat diambil adalah ukiran pa' bare allo memiliki makna yaitu supaya manusia yang datang dan turun dari tongkonan hendaknya senantiasa bersinar dan bercahaya dimana pun dia berada, dan pesan moralnya adalah manusia harus menjadi cahaya dan memberi harapan hidup bagi orang yang sedang berada dalam kegelapan hidup.

Ukiran pa' manuk londong memiliki makna yaitu menggambarkan suatu kepastian dan pesan moralnya adalah kita harus belajar dari sisi positif dari ayam jantan yang senantiasa bekerja keras, berani, dan disiplin dalam hal waktu.

Ukiran pa' tedong memiliki makna yaitu kesejahteraan dan pencapaian dari pemilik tongkonan, dan pesan moral dari ukiran ini adalah kita harus berusaha mencapai cita-cita agar kelak kita bisa mempersembahkan yang terbaik bagi orang yang kita cintai.

Ukiran pa' don bolu memiliki makna yaitu menggambarkan status pemilik dan menunjuk pada rasa sikap hormat yang tulus dari pemilik tongkonan atau rumpun keluarga dan pesan moral dari ukiran ini adalah kita harus senantiasa rendah hati dan hormat kepada sesama dalam kasih persaudaraan dan senantiasa hormat pada sang pencipta dalam setiap langkah kehidupan kita.

\section{Daftar Pustaka}

[1] Anggito, A., \& Setiawan, J. (2018). Metodologi Penelitian Kualitatif. CV Jejak (Jejak Publisher).
[2] Dewantara, D. (2017).Filsafat Moral Pergumulan Etis Keseharian Hidup Manusia(hal. 44-48). Yogyakarta: PT Kanisius.

[3] Endang, S. (2016). Pesan Moral Pada Film Dalam Mihrab Cinta. Yogyakarta: Universitas Islam Negeri Sunan Kalijaga.

[4] Hestiningdiyah, R. B. (2010). Pendidikan moral Studi analisis terhadap penanaman nilai-nilai moral siswa MAN 1 Magelang, 5.Literasi Media Publishing.

[5] Mamik. (2015). Metodologi Kualitatif. Sidoarjo: Zifatama Publisher.

[6] Manesah, D., Minawati, R., \& Nursyirwan. (2018). Analisis Pesan Moral Dalam Film Jangan Baca Pancasila Karya Rafdi Akbar, 2-3.

[7] Moleong, L. J. (2000). Metodologi Penelitian Kualitatif. Bandung: PT Remaja Rosdakarya.

[8] Mudana, I., \& Atmaja, N. B. (2018). Ilmu Sosial Dan Budaya Brorientasi Integrasi Nasional Dan Harmoni Sosial Berbasis Tri Hita Karana. Depok: Pt Rajagrafindo Persada.

[9] Narbuko, D., \& Achmadi, D. (2007). Metodologi Penelitian. Jakarta: PT Bumi Aksara.

[10] Panganna', R. S. (2018). Bisikan suci passura' Toraya. Jawa Tengah Indonesia: Nugra Media.

[11] Rahayu, W. (2017). Tongkonan Mahakarya Arsitektur Tradisional Suku Toraja. Rawamangun Jakarta Timur : Badan Pengembangan dan Pembinaan Bahasa.

[12] Rukin. (2019). Metodologi Penelitian Kualitatif. Takalar: Yayasan Ahmar Cendekia Indonesia. 
[13] Salam, S., Husain, M., \& Tangsi. (2015). "Pendidikan Seni Kerajinan-

Ukir di Kete' Kesu Kabupaten Toraja-Utara" dalam Konstelasi Kebudayaan Indonesia. Surabaya: Bintang Surabaya.

[14] Siyoto, S., \& Sodik, A. (2015). Dasar Metodologi Penelitian. Yogyakarta: L (Anggito \& Setiawan, 2018)

[15] Sugiarto, E. (2015). Menyususn Proposal Penelitian Kualitatifskripsi Dan Tesis hal 12). Yogyakarta: Suaka Media.

[16] Sugiyono, P. (2017). Metode Penelitian Pendidikan Pendekatan Kuantitatif, Kualitatif, dan $R \& D$. Bandung: Alvabeta.

[17] Susilawati, M., Suryanti, C., \& Koesbyanto. JA, D. (2010). Urgensi Pendidikan Moral Suatu Upaya Membangun Komitmen Diri. Yogyakarta: Surya Perkasa.
[18] Zuriah, D. (2006). Metodologi Penelitian Sosial Dan Pendidikan. Jakarta: PT Bumi Aksara.

\section{Profil Penulis 1}

Yohanis Padallingan, lahir di Sa'dan Ulusalu pada 5 Juni 1992. Menyelesaikan S1 pada progam studi Pendidikan Guru Sekolah Dasar Universitas Kristen Indonesia Toraja di tahun 2015 dan menyelesaikan S2 pada program studi Pendidikan Dasar Universitas Negeri Surabaya. Saat ini penulis merupakan dosen tetap pada progam studi PGSD UKI Toraja

\section{Profil Penulis 2}

Dion Aryo Nugraha Pongdatu, lahir di Rantepao pada 18 Mei 1988. Menyelesaikan S1 pada progam studi Sistem Informasi STMIK Dipanegara di tahun 2013 dan menyelesaikan S2 pada program studi Sistem Informasi Universitas Komputer Indonesia. Saat ini penulis merupakan dosen tetap pada program studi Teknik Informatika UKI Toraja 